\title{
Interspecific Crosses between Rhizobium leguminosarum and $R$. meliloti: Formation of Haploid Recombinants and of R-primes
}

\author{
By ANDREW W. B. JOHNSTON, SUE M. SETCHELL \\ AND JOHN E. BERINGER \\ John Innes Institute, Colney Lane, Norwich NR4 7UH
}

(Received 22 August 1977)

\begin{abstract}
Using R68.45 as a conjugative plasmid in crosses between strains of Rhizobium leguminosarum and $R$. meliloti, transfer of chromosomal genes occurred. Haploid recombinants were formed in which rif and str alleles were transferred from $R$. leguminosarum to $R$. meliloti. In crosses in the reverse direction haploid recombinants arose at barely detectable frequencies and progeny were isolated which were high frequency donors of the selected allele. Genetic evidence showed that such progeny harboured R-primes in which sections of the $R$. meliloti chromosome were inserted into R68.45. Four different classes of R68.45-prime, each carrying a different prototrophic marker, were obtained.
\end{abstract}

\section{INTRODUCTION}

Some plasmids can incorporate sections of bacterial chromosomes in vivo to form primes. These have been of great value in the study of gene function and organization. Best known are the F-primes of Escherichia coli (Low, 1972), but more recently primes of the sex plasmid SCP1 have been found in Streptomyces coelicolor (Hopwood \& Wright, 1973, 1976a). Chromosomal genes have been inserted into P1 group $\mathrm{R}$ plasmids in $E$. coli (Olsen \& Gonzalez, 1974), Klebsiella pneumoniae (Dixon, Cannon \& Kondorosi, 1976) and Pseudomonas aeruginosa (Hedges, Jacob \& Crawford, 1977) and these primes are of particular interest because P1 plasmids have a very wide host range among Gram-negative bacteria (Olsen \& Shipley, 1973). This allows the functions of genes on R-primes to be examined in different species and genera. For example, the expression of the $K$. pneumoniae nif genes has been studied in several genera (Dixon et al., 1976; Cannon \& Postgate, 1976), and the function of the $P$. aeruginosa trp genes has been studied in $E$. coli (Hedges et al., 1977) as have the $E$. coli trp genes in $P$. aeruginosa (Nagahari, Sano \& Sakaguchi, 1977).

Another property of P1 group R plasmids is their ability to mobilize chromosomal genes in different genera: P. aeruginosa (Haas \& Holloway, 1976), E. coli (Beringer \& Hopwood, 1976), Rhizobium spp. (Johnston \& Beringer, 1977; Meade \& Signer, 1977; Kondorosi et al., 1977) and Acinetobacter calcoaceticus (Towner \& Vivian, 1976).

We show here that R68.45 can mediate recombination between Rhizobium meliloti and $R$. leguminosarum. We have isolated R-primes carrying segments of the $R$. meliloti chromosome and found that genes on the inserted regions were expressed in $R$. leguminosarum.

\section{METHODS}

Bacterial strains and plasmids are shown in Table 1.

Media. The complete (TY) and minimal (Y) media for Rhizobium spp. were described by Beringer (1974). The complete (NA) and minimal media for $E$. coli and $P$. aeruginosa were described by Beringer, Hoggan \& Johnston (1978). Lennox Broth Agar (LBA) was described by Miller (1972). 
Table 1. Bacterial strains and plasmids

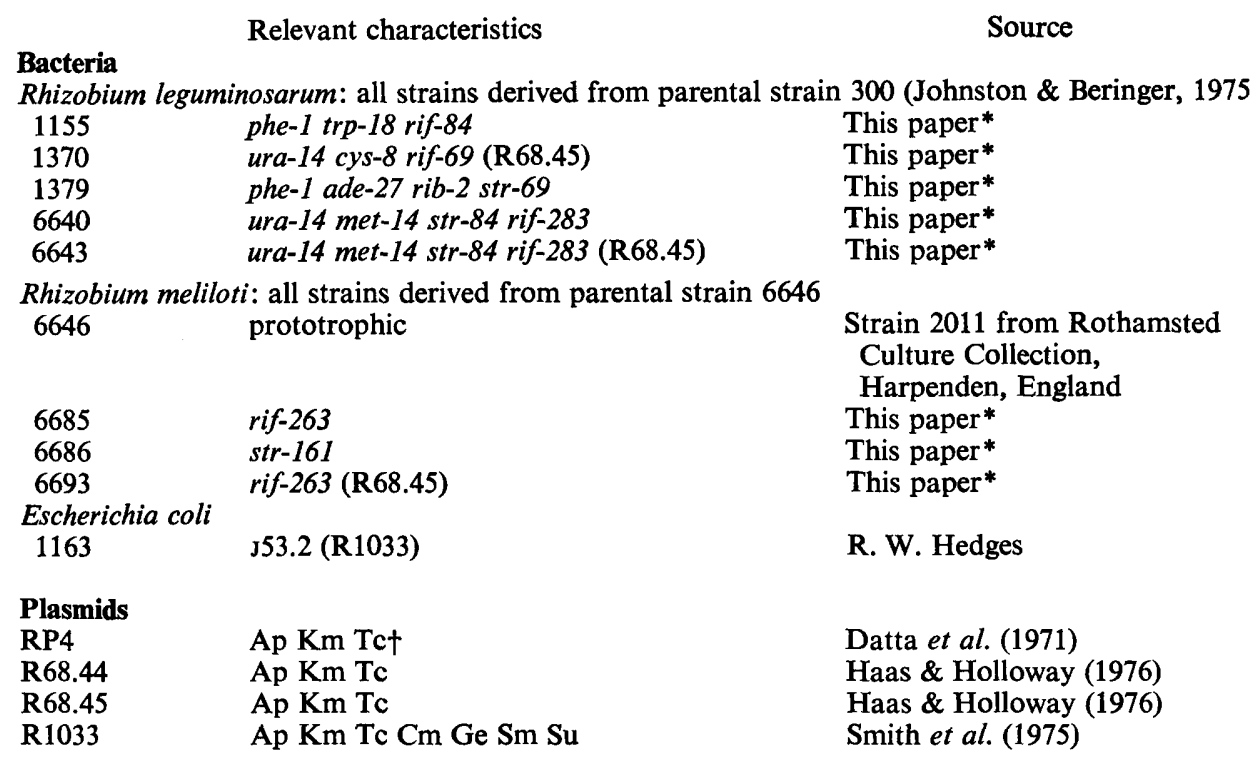

* Auxotrophic mutations in Rhizobium strains were induced by $N$-methyl- $N^{\prime}$-nitro- $N$-nitrosoguanidine; antibiotic resistant mutations were spontaneous (Beringer, 1974). $\mathbf{R}$ plasmids were introduced into Rhizobium strains by conjugal transfer from appropriate $\mathrm{R}^{+}$strains of $E$. coli, $P$. aeruginosa or $R$. leguminosarum.

$\dagger$ Abbreviation of antibiotic resistance markers: Ap, ampicillin; Cm, chloramphenicol, Ge, gentamicin; $\mathrm{Km}$, kanamycin; Sm, streptomycin; Su, sulphonamides; Tc, tetracycline.

Growth of bacteria was as described by Beringer et al. (1978).

Bacterial mating. Transfer and recombination frequencies were estimated quantitatively by the method of Jacob et al. (1976). Recombinants were analysed as described by Beringer \& Hopwood (1976).

For patch crosses, loopfuls of each parental culture were mixed on the surface of a TY plate which was incubated for $48 \mathrm{~h}$ before being replicated to an appropriate selective medium. The selective plates were incubated at $28^{\circ} \mathrm{C}$ for $3 \mathrm{~d}$. High frequency transfer of a marker was indicated by confluent growth on the selective plates, while 'normal' levels of transfer seldom gave more than one or two colonies per patch.

Plant inoculation tests. Peas (Pisum sativum var. Dark Skin Perfection) were inoculated and scored for nodulation as described by Beringer (1974). Seedlings of lucerne (Medicago sativa var. du Puits) were grown on agar slants in test tubes as described for clover by Johnston \& Beringer (1977). Acetylene reduction assays on root systems were as described by Johnston \& Beringer (1975). Peas and lucerne are the normal hosts for $R$. leguminosarum and $R$. meliloti respectively.

\section{RESULTS}

\section{Transfer of chromosomal genes between $R$. leguminosarum and $R$. meliloti}

Transfer of rif and str alleles from $R$. leguminosarum to $R$. meliloti. In R. leguminosarum, rif and str genes are closely linked (Beringer \& Hopwood, 1976). We made use of this fact to determine whether R68.45 could promote the co-transfer of rif and str from R. leguminosarum to $R$. meliloti (Table 2). When each antibiotic resistance was selected alone, and when the donor was $\mathrm{R}^{+}$, two sizes of $\boldsymbol{R}$. meliloti colonies were observed: large colonies of bacteria that were resistant to only one antibiotic and were probably spontaneous resistant mutants, and small colonies of bacteria that were usually (about $90 \%$ ) doubly resistant and were probably recombinants. When the donor was $\mathrm{R}^{-}$, there were no small colonies on either medium used for selecting singly-resistant colonies and no colonies of any sort on plates containing both antibiotics. This indicates that the presence of R68.45 in the donor was required for the generation of the small-colony recombinants. The frequency of the 
Table 2. Frequency of colony types in crosses between $R$. leguminosarum 6640 (ura-14 met-14 rif-283 str-84) and R. meliloti 6646, and between 6643

(6640 R68.45) and 6646

(a) Initial selective frequencies

Antibiotic(s) in selective medium

\begin{tabular}{|c|c|c|c|c|c|c|}
\hline \multirow{2}{*}{$\begin{array}{l}\text { Donor } \\
\text { strain }\end{array}$} & \multicolumn{2}{|c|}{ Rifampicin } & \multicolumn{2}{|c|}{ Streptomycin } & \multicolumn{2}{|c|}{ Rifampicin + Streptomycir } \\
\hline & Large* & Small* & Large & Small & Large & Small \\
\hline $\begin{array}{l}6640 \\
6643\end{array}$ & $\begin{array}{l}2 \times 10^{-7} \\
3 \times 10^{-7}\end{array}$ & $\begin{array}{c}<5 \times 10^{-9} \\
10^{-7}\end{array}$ & $\begin{array}{l}2 \times 10^{-7} \\
3 \times 10^{-7}\end{array}$ & $\begin{array}{c}<5 \times 10^{-9} \\
10^{-7}\end{array}$ & $\begin{array}{l}<5 \times 10^{-9} \\
<5 \times 10^{-9}\end{array}$ & $\begin{array}{c}<5 \times 10^{-9} \\
10^{-7}\end{array}$ \\
\hline
\end{tabular}

(b) Percentages of colonies which were both rif and str

\begin{tabular}{|c|c|c|c|c|}
\hline \multirow{3}{*}{$\begin{array}{l}\text { Donor } \\
\text { strain }\end{array}$} & \multicolumn{4}{|c|}{ Antibiotic in selective medium } \\
\hline & \multicolumn{2}{|c|}{ Rifampicin } & \multicolumn{2}{|c|}{ Streptomycin } \\
\hline & Large & Small & Large & Small \\
\hline $\begin{array}{l}6640 \\
6643\end{array}$ & $\begin{array}{r}<2 \% \\
10 \%\end{array}$ & $\overline{96 \%}$ & $\begin{array}{l}<2 \% \\
<3 \%\end{array}$ & $\overline{93 \%}$ \\
\hline
\end{tabular}

* Large and small colonies represent a subjective assessment of colony size based on the observation that there was not a continuum of colony size.

recombinants was about $10^{-7}$, which is about 10 -fold lower than in analogous crosses between strains of $R$. leguminosarum (Beringer et al., 1978).

In these crosses the frequency of R68.45 transfer to $R$. meliloti was about $1 \%$, the same as in crosses within $R$. leguminosarum (Beringer et al., 1978). However, whereas about $80 \%$ of the recombinants from crosses between strains of $R$. leguminosarum were $\mathrm{R}^{+}$(Beringer et al., 1978), there was no enrichment for $\mathbf{R}^{+}$transconjugants in $R$. leguminosarum $\times$ $R$. meliloti crosses. We have no explanation for this difference.

Twenty of the small-colony rif' str recombinants were grown on agar slopes without antibiotics and were re-plated on agar with and without antibiotics. Growth in the absence of rifampicin and streptomycin was normal but in the presence of either antibiotic the small-colony character was retained. This indicates that the small colony size was due to the poor expression of the antibiotic resistance rather than to a non-specific debilitation of $R$. meliloti due to the insertion of segments of $R$. leguminosarum chromosome.

These same 20 recombinants all effectively nodulated lucerne but failed to nodulate peas. Thus symbiotic proficiency of $R$. meliloti was not affected by the presence of $R$. leguminosarum rif or str alleles.

A cross between $R$. leguminosarum 1370 (ura-14 cys-8 rif-69 R68.45) and $R$. meliloti strain 6686 (str-161), with selection for the transfer of rif, again yielded a mixture of large and small colonies. All of a sample of 16 large colonies were rif str and all of 121 small ones were rif. The latter presumably arose by co-transfer of rif and str+. The fact that both str and $s t r^{+}$of $R$. leguminosarum could be transferred to and expressed in $R$. meliloti indicates that recombinants rather than partial diploids for this region were formed.

Transfer of rif and str alleles from $R$. meliloti to $R$. leguminosarum. Crosses were also done to see if R68.45 could mobilize rif or str alleles in the reverse direction, from derivatives of $R$. meliloti strain 6646 to $R$. leguminosarum. Four crosses of this type failed to generate any unambiguous recombinants but from one cross five colonies appeared to be due to co-transfer of rif and str $r^{+}$to $R$. leguminosarum at a frequency of about $4 \times 10^{-9}$. It is not known whether the barely detectable frequencies of transfer were due to a greatly decreased recombination frequency or to the inability of $R$. meliloti rif or str alleles to be expressed in $R$. leguminosarum. The limited expression of $R$. leguminosarum rif and str alleles in 
Table 3. Phenotypes of progeny in a cross between $R$. meliloti strain 6693 (rif-263 R68.45) and R. leguminosarum strain 1379 (phe-1 rib-2 ade-27 str-69)

\begin{tabular}{|c|c|c|c|c|c|}
\hline $\begin{array}{c}\text { Selective minimal } \\
\text { (Y) medium containing: }\end{array}$ & $\begin{array}{l}\text { Selected } \\
\text { allele }\end{array}$ & $\begin{array}{l}\text { No. of } \\
\text { colonies } \\
\text { tested }\end{array}$ & Relevant phenotype & $\begin{array}{l}\text { No. in } \\
\text { class }\end{array}$ & $\begin{array}{l}\text { Frequency of } \\
\text { transfer of } \\
\text { prototrophic } \\
\text { allele }\end{array}$ \\
\hline $\begin{array}{l}\text { Phenylalanine } \\
\text { + riboflavin } \\
\text { + streptomycin }\end{array}$ & ade- $27^{+}$ & 99 & $\begin{array}{l}\text { Phe- Rib- Str-r R68.45 } \\
\text { Str-r Rif-r R68.45 }\end{array}$ & $\begin{array}{l}74 \\
25^{*}\end{array}$ & $10^{-8}$ \\
\hline $\begin{array}{l}\text { Adenine } \\
\text { + riboflavin } \\
\text { + streptomycin }\end{array}$ & phe- $I^{+}$ & 109 & $\begin{array}{l}\text { Ade- Rib- Str-r R68.45 } \\
\text { Str-r Rif-r R68.45 }\end{array}$ & $\begin{array}{c}2 \\
107^{*}\end{array}$ & $4 \times 10^{-9}$ \\
\hline $\begin{array}{l}\text { Phenylalanine } \\
\text { + adenine } \\
\text { + streptomycin }\end{array}$ & $r i b-2^{+}$ & 100 & $\begin{array}{l}\text { Phe }^{-} \text {Ade }^{-} \text {Str-r } \\
\text { Str-r Rif-r R68.45 }\end{array}$ & $\stackrel{2}{98^{*}}$ & $\leqslant 10^{-9}$ \\
\hline
\end{tabular}

* These classes probably represent str mutants of the donor. They resembled $R$. meliloti in being less mucoid than $R$. leguminosarum and grew on LBA; R. meliloti grows on this medium (Meade \& Signer, 1977) but $R$. leguminosarum does not.

Table 4. Phenotypes of progeny in which a prototrophic allele was transferred with $\mathrm{R} 68.45$ from $R$. meliloti to $R$. leguminosarum

Strains
ML1 to ML20
ML21 and ML22
ML23 to ML30

Phenotype
Phe- Rib- Str-r R68.45
Rib- Ade- Str-r R68.45
Ura- Str-r Spc-r R68.45

\author{
Markers transferred from \\ R. meliloti \\ ade- $27^{+}$and $\mathrm{R} 68.45$ \\ phe $-1^{+}$and R68.45 \\ trp- $16^{+}$and $\mathbf{R} 68.45$
}

$R$. meliloti does imply that there may be problems in the normal expression of these alleles in different species.

Transfer of other alleles from $R$. meliloti to $R$. leguminosarum. In order to see if prototrophic alleles could be transferred from $R$. meliloti to $R$. leguminosarum, $R$. meliloti strain 6693 (rif-263 R68.45) was used as a donor to a number of multiply auxotrophic str strains of $R$. leguminosarum with selection for the transfer of prototrophy for one of the auxotrophic alleles (see Table 3 for an example). Many of the colonies on the selective plates were str mutants of the donor but some resembled $R$. leguminosarum and carried the appropriate non-selected markers. The $r i b-2^{+}$colonies could have been due to reversion because they were $\mathrm{R}^{-}$. However, all the ade $-27^{+}$and $p h e-1^{+}$colonies were $\mathrm{R}^{+}$although the overall frequency of R68.45 transfer was only about $2 \%$, suggesting that these colonies were not revertants but recombinants. In another cross, eight out of nine colonies selected for the transfer of trp- $16^{+}$received $\mathrm{R} 68.45$, although in seven other crosses, in which colonies were selected for transfer of various other alleles, there was no evidence of co-transfer of R68.45 with the selected prototrophic allele (frequencies $<10^{-9}$ ). All the colonies which appeared to have arisen by co-transfer of R68.45 with ade- $27^{+}$, phe- $1^{+}$or $\operatorname{trp}-16^{+}$were purified, grown on TY slants and numbered as in Table 4 . Since each of the strains in a particular class came from a single cross they may have been clonal.

\section{Characterization of $R$. leguminosarum 'recombinants'}

Because the transfer frequency of selected alleles in the crosses between $R$. meliloti donors and $R$. leguminosarum was so low the possibility was examined that the presumptive recombinants represented a special class with altered donor properties.

Donor properties. Each 'recombinant' was patch-crossed to a strain of $R$. leguminosarum carrying the same allele that was originally selected. For example, ML21 and ML22 were 


\section{Table 5. Segregation of markers among colonies of ML21 and $\mathrm{ML} 22$}

Cultures of ML21 and ML22 were grown non-selectively; 150 colonies from each were tested for segregation of relevant markers.

\begin{tabular}{clr} 
Strain & \multicolumn{1}{c}{ Relevant phenotype } & No. in class \\
ML21 & Str-r Ade- Rib- Km Tc* & 144 \\
& Str-r Phe- Ade- Rib- Km Tc & 1 \\
& Str-r Phe- Ade- Rib- & 1 \\
& Str-r Ade- Rib- Tc & 1 \\
Str-r Ade- Rib- Km & 3 \\
ML22 & Str-r Ade- Rib- Km Tc* & 147 \\
& Str-r Phe- Ade ${ }^{-}$Rib- Km & 3 \\
& * The initial phenotype.
\end{tabular}

crossed to strain 1155 (phe-1 trp-18 rif-84) with selection for phe-1+. The selective replica plates gave confluent growth, indicating high frequency transfer. In analogous crosses, strains ML1 to 20 and ML23 to 30 donated ade-27+ and trp-16+ respectively at high frequency.

Quantitative estimates of transfer frequencies for these alleles were made using two ML strains of each class as donors in crosses to appropriately marked strains of $R$. leguminosarum, with selection for the transfer of R68.45 and of ade-27+ (ML7 and ML18 as donors), phe- $1^{+}$ (ML21 and ML22) or trp-16+ (ML24 and ML27). The frequencies of transfer of R68.45 and the prototrophic markers were about $1 \%$. Fifty prototrophic colonies from each cross were picked; all were found to be resistant to kanamycin, indicating the presence of R68.45. Conversely 90 to $95 \%$ of colonies selected for R68.45 transfer were prototrophic. This very high frequency of co-transfer of R68.45 and prototrophy suggested that regions of the $R$. meliloti chromosome had been inserted into R68.45 to form R68.45-primes. This possibility was investigated in a number of ways.

Stability of R-primes. One of the features of plasmid primes is instability (Jacob \& Wollman, 1961; Hopwood \& Wright, 1973, 1976a; Dixon et al., 1976), so the stability of some of the putative R68.45-primes was tested. The strains were grown non-selectively on TY and plated for single colonies on TY. For each strain 150 colonies were tested for prototrophy and for the tetracycline and kanamycin resistance markers carried on R68.45 [carbenicillin resistance was not tested since this marker is not expressed well in $R$. leguminosarum strains (Beringer, 1974)]. The strains tested were those used in the crosses above, together with ML2 and ML25 which were much more unstable than the other strains.

Of the ML2 colonies $99 \%$ were $\mathrm{Ade}^{-}$, and of the ML25 colonies $77 \%$ were $\operatorname{Trp}^{-}$, although all the colonies still carried both $\mathrm{R}$ plasmid resistances. The other six strains were more stable: $95 \%$ or more of the colonies were ade- $27^{+}$, phe- $1^{+}$or $\operatorname{trp}-16^{+}$as appropriate. With the exception of ML21 and ML22 all colonies were resistant to both antibiotics, even when the prototrophic marker was lost, although in most cases the resistance to tetracycline was poorly expressed. For ML21 and ML 22 there was segregation not only of phe-1 but also of sensitivity to one or other antibiotic; one colony was sensitive to both antibiotics and may represent loss of the whole plasmid (Table 5). Segregation of antibiotic sensitivity in R-prime strains has been reported (Dixon et al., 1976).

Elimination of R-primes. If indeed R68.45-primes had been formed, the ML strains should have tended to lose their prototrophic marker if a plasmid of the same incompatibility group were introduced into them to replace R68.45. This was found to be so. When R1033 was transferred from $E$. coli strain 1163 into ML7, ML18, ML21, ML22, ML24 and ML27 by selecting for gentamicin resistance, 90 to $95 \%$ of the transconjugants were Ade-, Phe ${ }^{-}$or Trp ${ }^{-}$as appropriate. The nature of the minority of R1033 transconjugants which had not lost their prototrophic marker is not clear. Since R1033 determines resistance to the same antibiotics as R68.45 as well as to gentamicin, it was not possible to determine whether or not the resident 


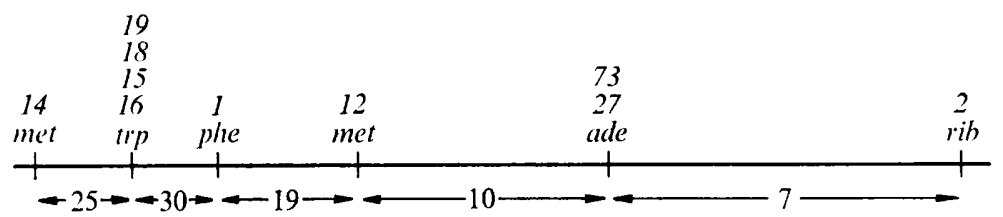

Fig. 1. Positions of relevant alleles on the chromosome of $R$. leguminosarum (from Beringer et al., 1978 , and unpublished). Numbers above the markers are allele numbers, and numbers below the line are co-inheritance percentages of pairs of alleles.

plasmid had been eliminated. The similarity in the antibiotic resistance markers and presumably transfer genes of R68.45 and R1033 may allow recombination to occur between them.

The genetic evidence so far presented indicated that the ML strains harboured R-primes in which sections of the $R$. meliloti chromosome had been inserted into R68.45. Accordingly these plasmids in the ML strains 7, 18, 21, 22, 24 and 27 were designated pAJ7, 18, 21, 22, 24 and 27 respectively.

How far do the R-primes extend? Figure 1 gives the map positions of relevant alleles on the $R$. leguminosarum chromosome (Beringer et al., 1978). Crosses were made between certain ML strains and appropriately marked $R$. leguminosarum recipients to see if the R68.45primes extended to cover a neighbouring allele as well as the selected marker and also to see if they mobilized neighbouring genes at higher frequencies than did R68.45. Other plasmid primes are known to enhance gene transfer of the chromosome in the region of the inserted segment (Pittard, Loutit \& Adelberg, 1963; Hopwood \& Wright, 1976b). However, it was found that pAJ7 and pAJ18 failed to cover rib-2 and met-12, pAJ21 and pAJ22 did not cover met-12 or trp-16 and pAJ24 and pAJ27 did not cover phe- 1 or met-14. No enhancement of the transfer of any of the flanking markers was detected. The possibility that some of the inserted segments in R68.45 did extend as far as one of the flanking markers but were unable to express in $R$. leguminosarum cannot be eliminated. However, in the region phe-1trp-16 this cannot apply since it is clear that $R$. meliloti genes equivalent to those defined by these alleles can work in $R$. leguminosarum. It should also be mentioned that the identity of gene order in these two species remains to be established even though preliminary genetic maps for both species exist (Meade \& Signer, 1977; Kondorosi et al., 1977; Beringer et al., 1978). If, for example, the genes defined by phe-1 and trp-16 are not as closely linked in $R$. meliloti there would be no chance for the phe-1 and trp-16 alleles to be covered by the same R68.45-prime.

Transfer of $\mathrm{pAJ} 18$ and $\mathrm{pAJ} 24$ to $R$. leguminosarum strains with different ade and trp alleles. Strains ML18 and ML24 were patch-crossed to $R$. leguminosarum strains carrying different $a d e$ and $\operatorname{trp}$ alleles respectively. Of eight ade alleles, ML18 (the ade-27+ donor) donated only ade-73+ at high frequency; ade-73 maps near ade-27 (Fig. 1). Three ade alleles mapping elsewhere on the chromosome and four unmapped alleles failed to be covered. The mapped trp alleles of $R$. leguminosarum occur in two regions (Beringer et al., 1978): trp-15, -16, -18 and -19 lie between phe-1 and met-14 (Fig. 1) while trp-12 and -14 map together at another region. When ML24 (the $\operatorname{tr} p-16^{+}$donor) was patch-mated to strains carrying $\operatorname{tr} p$ alleles there was high frequency donation of $\operatorname{trp}-15^{+},-18^{+}$and $-19^{+}$and of the wild-type alleles of three other unmapped $\operatorname{trp}$ mutations but not of $\operatorname{trp}-12^{+}$and $-14^{+}$. This agrees with the mapping data and suggests a similar arrangement of trp alleles in $R$. leguminosarum 300 and $R$. meliloti 6646 . The colony size of the $t r p-15^{+},-16^{+}$and $-18^{+}$transconjugants was normal but the colonies selected for trp-19+ transfer grew slowly, suggesting poor expression in $R$. leguminosarum of the $R$. meliloti gene equivalent to that defined by trp-19. Also, when an $R$. trifolii strain carrying a trp allele (trp-47) which mapped in the same region as trp-16 of $R$. leguminosarum (A. W. B. Johnston, unpublished results) was used as a recipient in a cross with ML24, transfer of $\operatorname{trp}-47^{+}$occurred at high frequency. 
Table 6. Screening of recombinants formed in $R$. leguminosarum $\times R$. leguminosarum crosses to determine the frequency of $R$-prime formation

$\begin{array}{lccl}\text { Marker } & \begin{array}{c}\text { No. of recombinants } \\ \text { tested }\end{array} & \text { R plasmid* } & \text { No. of R-primes† } \\ \text { cys }-9^{+} & 44 & \text { RP4 } & 0 \\ \text { phe }-1^{+} & 28 & \text { RP4 } & 0 \\ \text { phe }-1^{+} & 65 & \text { R68.44 } & 2 \text { (probably clonal) } \neq \\ \text { met }-11^{+} & 22 & \text { R68.44 } & 0 \\ \text { rib }-2^{+} & 16 & \text { R68.44 } & 0 \\ \text { ade }-26^{+} & 17 & \text { R68.44 } & 0 \\ \text { liv- } 6^{+} & 9 & \text { R68.44 } & 0 \\ \text { ura }-14^{+} & 305 & \text { R68.45 } & 0 \\ \text { met }-14^{+} & 63 & \text { R68.45 } & 0 \\ \text { phe }-1^{+} & 102 & \text { R68.45 } & 1\end{array}$

* The RP4 and R68.44 recombinants tested here arose at frequencies of $10^{-8}$; with $\mathrm{R} 68.45$ the frequencies were about $10^{-6}$.

$+\mathbf{R}^{+}$recombinants for each marker were collected from different crosses involving the same $\mathbf{R}$ plasmid and patch-mated to a suitable $R$. leguminosarum recipient, as described in Methods.

† These two phe- $I^{+}$R-primes were obtained from recombinants arising in the same cross.

Although pAJ24 failed to mobilize phe- $1^{+}$and $m e t-14^{+}$at higher frequencies than did R68.45, the closely linked trp-15, -18 and -19 alleles might have been transferred by high frequency mobilization rather than by virtue of the presence on the plasmid of the wild-type genes corresponding to the mutations. However, $\operatorname{trp}-15^{+},-18^{+}$and $-19^{+}$were transferred at similar frequencies to $\operatorname{trp}-16^{+}: 100 \%$ of $\mathrm{Trp}^{+}$transconjugants received $\mathrm{R} 68.45$ and more than $90 \%$ of the $\mathrm{R}^{+}$transconjugants were $\operatorname{Trp}^{+}$. These results suggest tha $\mathrm{pAJ} 24$ covered trp-15, -18 and -19 rather than that these alleles were mobilized from the chromosome.

\section{Isolation of $R$-primes in $R$. leguminosarum}

R68.45-primes might have been isolated fairly readily in crosses between $R$. meliloti and $\boldsymbol{R}$. leguminosarum because crossing-over was greatly reduced, giving enrichment for the transfer of alleles via R68.45-primes. The use of interspecific crosses to produce $\mathbf{R}$ plasmid primes in other bacteria has been reported (Hedges et al., 1977); this method is analogous to the original use of $\mathrm{Rec}^{-}$recipients in plasmid prime selection (Low, 1968).

In this study the frequencies of R68.45-prime formation ranged from $10^{-8}$ to $<10^{-10}$. This implies that in crosses between strains of $R$. leguminosarum where the recombination frequency is about $10^{-6}$ (Beringer \& Hopwood, 1976) as many as $1 \%$ of 'recombinants' might in fact be due to the formation of R-primes. This possibility was tested by screening $\mathrm{R}^{+}$recombinants of $R$. leguminosarum which had inherited a single marker from an $R$. leguminosarum donor for their ability to donate that marker at high frequency in patch crosses. The presence of an R-prime was then confirmed by testing the frequency of transfer of the marker relative to the $R$ plasmid and by looking for its elimination after replacing the R plasmid by another P1 plasmid. Both procedures were performed as described above for the $R$. meliloti R-primes. The data in Table 6 show that R-primes were found at low frequency among recombinants isolated from crosses involving the plasmids R68.44 and R68.45.

\section{DISCUSSION}

In crosses between strains of $R$. leguminosarum and $R$. meliloti two types of R68.45mediated chromosomal gene transfer were observed: the formation of true haploid recombinants and the production of $\mathrm{R}$-primes.

The transfer of rif and str alleles from $R$. leguminosarum to $R$. meliloti appeared to involve the production of haploid recombinants since both $s t r$ and $s t{ }^{+}$alleles could be transferred 
and expressed and were co-inherited at high frequency with rif. The frequency of inheritance was about 10 -fold lower than in similar crosses between strains of $R$. leguminosarum (Beringer et al., 1978) or in interspecific crosses between $R$. leguminosarum, $R$. trifolii and $R$. phaseoli (Johnston \& Beringer, 1977). This may reflect the fact that these last three species are very closely related and are taxonomically more distant from $R$. meliloti (Graham, 1964). The expression of the rif and str alleles in the $R$. meliloti recombinants was poor, as judged by their slow growth rate in the presence of either antibiotic.

In crosses in which $R$. meliloti was the donor to $R$. leguminosarum, transfer of rif and str alleles was barely detectable (frequency $\leqslant 10^{-9}$ ). We do not know why the frequency of transfer of such alleles is some 100 -fold lower in this direction than from $R$. leguminosarum to $R$. meliloti. It could be due to a lowered recombination or transfer frequency, or to the inability of $R$. meliloti rif or str alleles to be expressed in $R$. leguminosarum. Another explanation could be that in $R$. leguminosarum there are essential genes closely linked to $r i f / s t r$ which cannot be functionally replaced by corresponding genes of $R$. meliloti.

When selection was made for the transfer of various prototrophic alleles from $R$. meliloti to $R$. leguminosarum the frequency was low and for some alleles no transfer was detected. Crosses in which selection was made for the transfer of $p h e-1^{+}$, ade-27+ and $\operatorname{trp}-16^{+}$from $R$. meliloti to $R$. leguminosarum yielded progeny which could be interpreted as carrying R68.45-primes. These were unstable, yielding auxotrophic segregants at frequencies of 5 to $99 \%$. It is not known whether the loss of the prototrophic marker was due to loop-out of the inserted region or to conversion to a homogenote by some type of recombination event with the chromosome (Jacob \& Wollman, 1961; Hopwood \& Wright, 1973, 1976a). The apparently low recombination frequency between $R$. meliloti and $R$. leguminosarum and the fact that in some cases loss of the prototrophic allele was accompanied by the loss of one of the antibiotic resistance markers on R68.45 possibly favours the former general explanation.

In E. coli, F-primes mobilize chromosomal genes close to the region inserted in the plasmid at much higher frequencies (up to 1000-fold) than does F (Pittard et al., 1963). A lesser enhancement was also found in S. coelicolor with some SCP1-primes (Hopwood \& Wright, $1976 b$ ). The enhanced donor ability of F-primes is due to an interaction with the chromosome through a recombination event between the chromosome and the homologous region on the plasmid (Pittard \& Adelberg, 1963). None of the R68.45-primes carrying sections of the $R$. meliloti chromosome mobilized adjacent markers at high frequency. The DNA sequences on the plasmid and the chromosome of $R$. leguminosarum may be sufficiently different to prevent or reduce recombination between the two. Jacob et al. (1976) constructed in vitro a derivative of the P group plasmid RP4 which contained a region of the $R$. leguminosarum (strain 300) chromosome but it was no better at mobilizing the chromosome of $R$. leguminosarum even though there was complete homology between the inserted region and the chromosome. The failure of R-primes to act as better sex factors may reflect the apparently poor recombination ability of $R$. leguminosarum (Beringer et al., 1978).

The expression of some $R$. meliloti genes in $R$. leguminosarum was not always complete. The pAJ24 plasmid donated prototrophy to an $R$. leguminosarum trp-19 strain at high frequency but the transconjugants grew slowly in the absence of tryptophan. In addition, in a cross between $R$. meliloti strain 6693 and an $R$. leguminosarum strain carrying cys- 8 , slow growing progeny were isolated. These were found to be high frequency donors of $c y s-8^{+}$ and they proved to be R68.45cys $-8^{+}$primes. However, the poor growth rate of these strains made the scoring procedures less clear than for the other primes and data on them were not included. Nevertheless there appear to be at least two prototrophic alleles of $R$. melilot $i$ which fail to express properly in a member of the same genus.

The fact that the R-primes described here were derivatives of a plasmid with a broad host range means that the expression of Rhizobium genes in other bacterial genera can be tested. We have found (unpublished observations) that the pAJ24 prime in strain ML24 donated 
$\operatorname{Trp}^{+}$at high frequency to a strain of $P$. aeruginosa which carried a $\operatorname{trp} F$ mutation. Out of 100 transconjugants selected for transfer of carbenicillin resistance 89 were $\mathrm{Trp}^{+}$, and of $100 \mathrm{Trp}^{+}$transconjugants all were carbenicillin-resistant. This indicated that $\mathrm{pAJ} 24$ contained a gene corresponding to $P$. aeruginosa $\operatorname{trpF}$ (which specifies phosphoribosyl anthranilate isomerase) and that the Rhizobium gene can express in the new host. Such crosses using other Rhizobium primes should facilitate the allocation of genes concerned with particular biosynthetic steps to regions of the Rhizobium chromosomes.

The isolation of R-primes in Rhizobium should assist in its genetic analysis since it offers the potential for dominance and complementation studies. It will be of particular interest if, in the future, R-primes can be isolated which contain genes concerned with symbiotic characters since these could be of help in elucidating the expression and organization of such genes.

We would like to thank those workers who supplied bacterial strains. We are grateful to Professor D. A. Hopwood and Dr N. J. Brewin for constructive criticism and to S. A. Hoggan for technical assistance.

\section{REFERENCES}

BERINGER, J. E. (1974). R-factor transfer in Rhizobium leguminosarum. Journal of General Microbiology 84, 188-198.

Beringer, J. E., Hoggan, S. A. \& Johnston, A. W. B. (1978). Linkage mapping in Rhizobium leguminosarum by means of $\mathbf{R}$ plasmid-mediated recombination. Journal of General Microbiology 104, 201-207.

Beringer, J. E. \& Hopwood, D. A. (1976). Chromosomal mobilization and mapping in Rhizobium leguminosarum. Nature, London 264, 291-293.

Cannon, F. C. \& Postgate, J. R. (1976). Expression of Klebsiella nitrogen fixation genes (nif) in Azotobacter. Nature, London 260, 271-272.

Datta, N., Hedges, R. W., Shaw, E. J., Sykes, R. B. \& Richmond, M. H. (1971). Properties of an $\mathbf{R}$ factor from Pseudomonas aeruginosa. Journal of Bacteriology 108, $1244-1249$.

Dixon, R., Cannon, F. \& Kondorosi, A. (1976). Construction of a $\mathbf{P}$ plasmid carrying nitrogen fixation genes from Klebsiella pneumoniae. Nature, London 260, 268-271.

GrahaM, P. H. (1964). The application of computer techniques to the taxonomy of the root-nodule bacteria of legumes. Journal of General Microbiology 35, 511-517.

HaAs, D. \& Holloway, B. W. (1976). R factor variants with enhanced sex factor activity in Pseudomonas aeruginosa. Molecular and General Genetics 144, 243-251.

Hedges, R. W., Jacob, A. E. \& Crawford, I. P. (1977). Wide ranging plasmid bearing the Pseudomonas aeruginosa tryptophan synthase genes. Nature, London 267, 283-284.

Hopwood, D. A. \& WRIGHT, H. M. (1973). A plasmid of Streptomyces coelicolor carrying a chromosomal locus and its inter-specific transfer. Journal of General Microbiology 79, 331-342.

Hopwood, D. A. \& WRIGHT, H. M. (1976a). Genetic studies on SCP1-prime strains of Streptomyces coelicolor. Journal of General Microbiology 95, 107-120.

Hopwood, D. A. \& WRIGHT, H. M. (1976b). Interactions of the plasmid SCP1 with the chromosome of Streptomyces coelicolor A3(2). In Second International Symposium on the Genetics of Industrial Microorganisms, pp. 607-619. Edited by K.D. Macdonald. London and New York: Academic Press.

JaCob, A. E., Cresswell, J. M., Hedges, R. W., Coetzee, J. N. \& Beringer, J. E. (1976). Properties of plasmids constructed by the in vitro insertion of DNA from Rhizobium leguminosarum or Proteus mirabilis into RP4. Molecular and General Genetics 147, 315-323.

JACOB, F. \& Wollman, E. L. (1961). Sexuality and the Genetics of Bacteria. New York: Academic Press.

Johnston, A. W. B. \& BerInger, J. E. (1975). Identification of the Rhizobium strains in pea root nodules using genetic markers. Journal of General Microbiology 87, 343-350.

Johnston, A. W. B. \& Beringer, J. E. (1977). Chromosomal recombination between Rhizobium species. Nature, London 267, 611-613.

Kondorosi, A., Kiss, G. B., Sorrai, T., Vincze, E. \& DANSALVI, Z. (1977). Circular linkage map of the Rhizobium meliloti chromosome. Nature, London 268, 525-527.

Low, K. B. (1968). Formation of merodiploids in matings with a class of $\mathrm{Rec}^{-}$recipient strains of Escherichia coli $\mathrm{k} 12$. Proceedings of the National Academy of Sciences of the United States of America 60, 160-167.

Low, K. B. (1972). Escherichia coli K-12 F-prime factors, old and new. Bacteriological Reviews 36, 587-607.

Meade, H. M. \& Signer, E. R. (1977). Genetic mapping in Rhizobium meliloti. Proceedings of the National Academy of Sciences of the United States of America 74, 2076-2078.

Miller, J. H. (1972). Experiments in Molecular Genetics. New York: Cold Spring Harbor Laboratory.

Nagahari, K., Sano, Y. \& Sakaguchi, K. (1977). Derepression of $E$. coli trp operon on interfamilial transfer. Nature, London 266, 745-746.

Olsen, R. H. \& Gonzalez, C. (1974). Escherichia coli gene transfer to unrelated bacteria by a 
histidine operon-RP1 drug resistance plasmid complex. Biochemical and Biophysical Research Communications 59, 377-385.

OlsEN, R. H. \& ShIPLeY, P. (1973). Host range and properties of the Pseudomonas aeruginosa $\mathbf{R}$ factor R1822. Journal of Bacteriology 113, 772-780.

Pittard, J. \& Adelberg, E. A. (1963). Gene transfer by $\mathrm{F}^{\prime}$ strains of Escherichia coli K-12 II. Interaction between F-merogenote and chromosome during transfer. Journal of Bacteriology 85, 14021408.

Pittard, J., Loutit, J. S. \& Adelberg, E. A. (1963).
Gene transfer by $F^{\prime}$ strains of Escherichia coli $\mathrm{K}-12 \mathrm{I}$. Delay in initiation of chromosome transfer. Journal of Bacteriology 85, 1394-1401.

Smith, D. I., Gomez Lus, R., Rubio Calvo, M. C., DatTA, N., JACOB, A. E. \& Hedges, R. W. (1975). Third type of plasmid conferring gentamicin resistance in Pseudomonas aeruginosa. Antimicrobial Agents and Chemotherapy 8, 227-230.

TOWNER, K. J. \& VIVIAN, A. (1976). RP4-mediated conjugation in Acinetobacter calcoaceticus. Journal of General Microbiology 93, 355-360. 